\title{
«Eternal Images» of Antiquity: Functional Analysis in the Scope of the Late 20th - Early 21st Centuries Visual Culture
}

\author{
Nina V. Getashvili** \\ The Russian Academy of Painting, Sculpturing \\ and Architecture of Ilya Glazunov \\ Moscow, Russian Federation
}

Received 10.10.2021, received in revised form 10.12.2021, accepted 18.01.2022

\begin{abstract}
Traced the desire of star artists from France, Italy, Spain, Great Britain, Russia, different generations and with fundamentally different worldview foundations of creativity, in recent decades to include antique motifs in their imaginative programs; moreover, making them the translators of individual artistic expressions reflecting sociocultural reception. The portrayal of ancient images, on different aesthetic and worldview bases, are present in the experimental works of the modernism, in the postmodernism (which became a reflection of the collapse of the whole picture of the world observed in modern psychology, philosophy, history), are a means of actualization gender issues, the problems of the LDF community, a reflection of glamorous aesthetics, arise in examples of street art and arte-pover, elite and mass culture, etc. For the first time in many centuries, «antique» sculptures appear at city crossroads and squares, bearing signs of the formal vocabulary of new trends. Over the past more than half a century, the individual statements of artists, in an attempt to remain in the field of polemical discourse, in an effort to expand the boundaries of the norm, including the recently approved ones, took place within the framework of large-scale (it is important to be aware) conceptual projects, thematically completely based on the interpretation of the images of Antiquity, which takes place for the first time in the history of exhibition practice. Moreover, these projects sometimes seem to be milestones in the development of contemporary art.
\end{abstract}

Keywords: antique motifs, the modernism, the postmodernism, contemporary art.

Research area: art history.

Citation: Getashvili N. V. (2022). «Eternal images» of antiquity: functional analysis in the scope of the late 20 th - early 21 st centuries visual culture. J. Sib. Fed. Univ. Humanit. soc. sci., 15(1), 9-22. DOI: $10.17516 / 1997-1370-0873$

(C) Siberian Federal University. All rights reserved

* Corresponding author E-mail address: ninagallery@yandex.ru 


\title{
«Вечные образы» Античности
}

\section{и искусство второй половины XX - начала XXI века: опыт функционального анализа}

\author{
Н.В.Геташвили \\ Российская академия живописи, ваяния и зодчества Ильи Глазунова \\ Российская Федерация, Москва
}

\begin{abstract}
Аннотация. Прослеживается стремление ведущих художников Франции, Италии, Испании, Великобритании, России разных поколений и с принципиально различными мировоззренческими основами творчества включать в свои образные программы античные мотивы, более того, именно их делать трансляторами индивидуальных художественных высказываний, отражающих социокультурную рецепцию. Они обнаруживаются в экспериментальных произведениях позднего модернизма, в постмодернизме (ставшем отражением крушения цельной картины мира, наблюдаемой в современных психологии, философии, истории), оказываются средством актуализации гендерной проблематики, проблем ЛДФ-сообщества, отражением гламурной эстетики, возникают в примерах стрит-арта и арте-повера, элитарной и масскультуры и т. д.

Впервые за много веков на городских перекрестках и площадях появляются «античные» скульптуры, несущие на себе признаки формальной лексики новых направлений. За последние более чем полвека индивидуальные высказывания художников в попытках оставаться в поле полемического дискурса, в стремлении расширять границы нормы, в том числе недавно утвержденные, состоялись в рамках масштабных (это важно осознавать) концептуальных проектов, тематически полностью основанных на интерпретации образов античности, что происходит впервые в истории выставочной практики. Более того, эти проекты представляются подчас этапными вехами в развитии современного искусства.
\end{abstract}

Ключевые слова: образы античности, искусство модернизма, искусство XX века, постмодернизм, экспериментальное искусство.

Научная специальность: - 17.00 .04 изобразительное и декоративно-прикладное искусство и архитектура.

\section{Введение}

Внимательный взгляд на искусство последних десятилетий XX и начала третьего тысячелетия легко обнаружит широкий круг ярких представителей модернизма, постмодернизма и метамодернизма, в творчестве которых «вечные образы» продолжают играть важную роль. Сказанное тем более справедливо по отношению к Античности, обращение к которой многих крупнейших мастеров последних десятилетий сохранило за ней статус универсальной культурной парадигмы западного мира.
Сложение новой культуры XX века, как и мировоззренческих концепций, было в значительной мере инспирировано радикальными событиями, происходившими в общественной и научной сферах. К «зрелости» столетия пассионарная энергия антропосферы (как на созидание, так и на разрушение) не только не снизилась, но приобрела более грандиозный масштаб. Упомянем лишь военные катастрофы, крушение мировых империй, рождения и кончины новых государственных и политических объединений, создание атом- 
ной и водородной бомб, поставившее уже все человечество на грань существования, и т. д.

Тем не менее после Второй мировой войны, после Освенцима мир, пережив глубочайшую психологическую и культурную травму, вернулся к «стихам», к вечным ценностям гуманистического наследия, однако уже с «родимыми пятнами» пережитого. Античные «матрицы» на новой стадии культуры оказались насыщенными иными, чем прежде, смыслами, а значит, и функциями.

\section{Постмодернизм}

\section{и другие «икарийские игры»}

Протагонисты модернизма (Пикассо, Дали, Цадкин, Кирико и др.), сохранив творческий потенциал, харизму и свойское отношение к европейской культурной традиции, неизменный глубокий интерес к античному миру, продолжали оставаться «фигурами влияния» и стали в свою очередь «собеседниками», а подчас и ориентирами для своих младших современников, обращавшихся к этой теме. Следует подчеркнуть ключевое обстоятельство: представителям новых художественных движений в их формальных и идейных поисках уже не приходилось основываться на характерном для модернистов начала прошлого столетия протестном пафосе. Осознание возможностей решительного переосмысления формальных воплощений «вечных образов» как трансляторов новых смыслов уже совершилось в недавнем прошлом. Тем не менее послевоенное время, достаточно комфортное для скорой адаптации новых визуальных концепций, продолжает предлагать изобретательную вариативность в репрезентации образов античности. И прежде всего в рамках постмодернистских концепций.

Л. Стайнберг, американский критик, первым применивший термин «постмодернизм» в анализе процессов, происходящих в живописи, отмечает: «Картина изначально задумана как образ образа. Сама эта концепция гарантирует, что образ не будет непосредственным изображением миро- пространства, однако способен включить в себя любой опыт в качестве объекта репрезентации» (Stainberg, 2021). Искусство, по наблюдению Стайнберга, «перестает быть “окном в мир”, становясь частью хаотичного и разнонаправленного информационного потока, массмедийная мощность которого в 1960-е годы неизмеримо возрастала» (Andreeva, 2007). Культура в таком контексте становится второй природой (Rykov, 2010). Но еще до «классического» постмодернизма Ив Кляйн (1928-1962), которого называют одной из ключевых фигур послевоенного европейского искусства и важнейшим художником второй половины XX века, окрасил изобретенным им красочным составом, получившим наименование «Международный синий Кляйна» (International Klein Blue - IKB), статуи Венеры («The Venus of Alexandria (Venus Blue)») и Ники Самофракийской - эта работа 1962 года стала последней в его творчестве.

Так, IKВ как символ, по ощущению художника, бесконечности Вселенной, художника, для которого женское тело было не только излюбленным объектом, но и инструментом изображения, а до этого работавшего с абстрактными поверхностями, апроприирует классические образы. «Venus Blue», растиражированная фирмой Lalique, сделалась сувенирной продукцией, ориентированной на широкого потребителя. Подобное потребительское отношение к художественной эзотерике Кляйна побуждает в который раз вспомнить о справедливости тезисов эссе В. Беньямина (Walter Benjamin) о судьбах произведений искусства в эпоху его технической воспроизводимости и затронуть проблему экспансии образов Античности, трактованных новыми художниками, в массовую культуру, «утилизацию» их в «дизайне».

В 1960-м году Кляйн и его биограф, искусствовед, художественный критик Пьер Рестани Pierre Restany (к слову, придумавший для Кляйна термин «монохром» - le monochrome), обозначили отказ от царствующей в художественных умах абстракции и утвердили особую тенденцию в совре- 


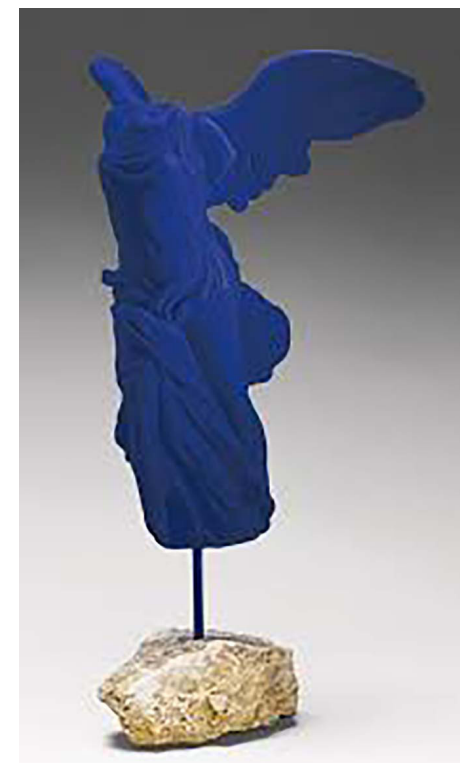

Ив Кляйн. Ника Самофракийская S9. 1962

Yves Klein. Nike of Samothrace S9. 1962

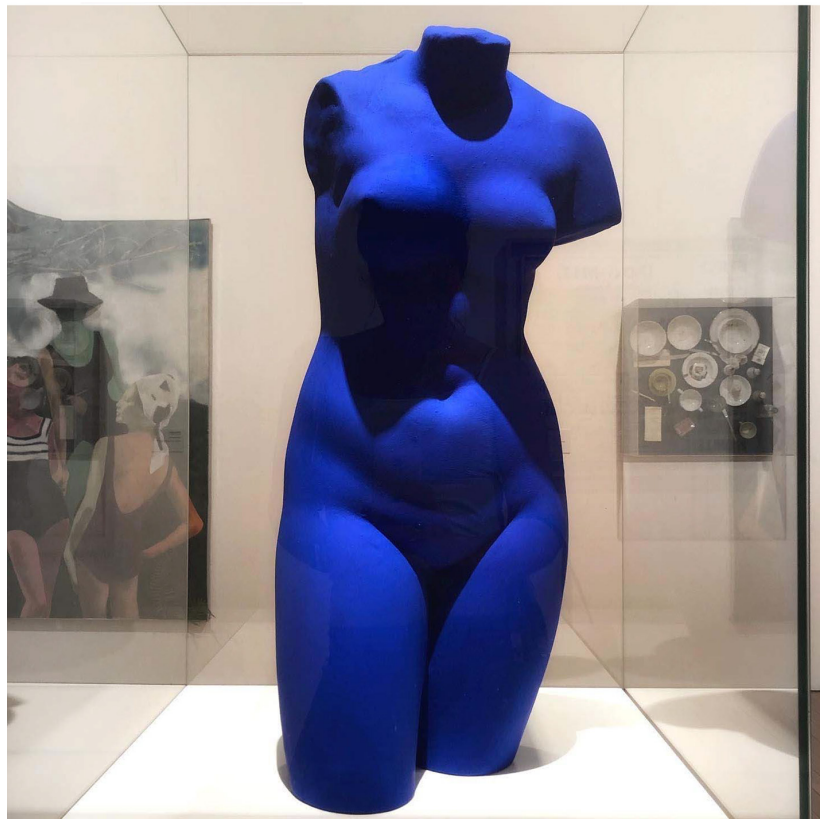

Ив Кляйн. Синяя Венера. Yves Klein. 1962 The Venus of Alexandria (Venus Blue). 1962 менном французском искусстве, названную новым реализмом (Nouveau Réalisme) (Busev, 2018). Среди девяти участников, подписавших их первую декларацию, были Арман и Сезар.

Образы богини любви в скульптурах ровесника и друга Кляйна французского художника и скульптора Армана Arman (Armand Pierre Fernandez) (1928-2005) во множестве вариаций Венеры Медичи и Венеры Милосской вполне могут конкурировать по количеству и по причудливости воплощения с далианскими. (Прямой «ссылкой» на творения Дали является его фигура бронзовой «Венеры побережья» Venus from the Sea Coast. (1990-1994), pacceченная лодочными винтами.)

Среди других примеров - «Античный автопортрет», Antique self-portrait «Анатомия желания» с расслоенной фигурой античной Венеры, «Венера с красными ногтями» Vénus aux Ongles Rouges/Venus with Red Nails (торс Венеры из полиэстера, наполненный женскими «кистями»), «Венера с долларами «Vénus Aux Dollars»» (Venus with dollars) и др. На самом деле стремле- ние использовать «обыденные» предметы в художественных произведениях или в качестве таковых вовсе не ново, и кубизм, а в большей степени дадаизм уже предоставляли подобные примеры. Параллельно с «новым реализмом» декларирует «красоту садового насоса» и поп-арт. Можно вспомнить также, что персонажи изысканных живописных фантазий Де Кирико («археологи», «беспокойные музы» и другие) не раз оказывались наполненными всевозможными предметами и фрагментами. Однако если формальные эффекты в метафизической живописи подчиняются напряжению высокой поэтической ноты, то Арман такую задачу перед собой не ставил. Между тем узнаваемый облик трансформированных античных богов и героев (кроме Венеры, это Эрос, Диана, Актеон, Геракл, Ника, эфеб и т. д.) все же привносит в восприятие армановских скульптур культурную многозначность. Более того, для зрителя, адаптировавшего в своем восприятии авторский прием «расчленения», подобные произведения обретают подчас и декоративную значимость как в выставочном или 


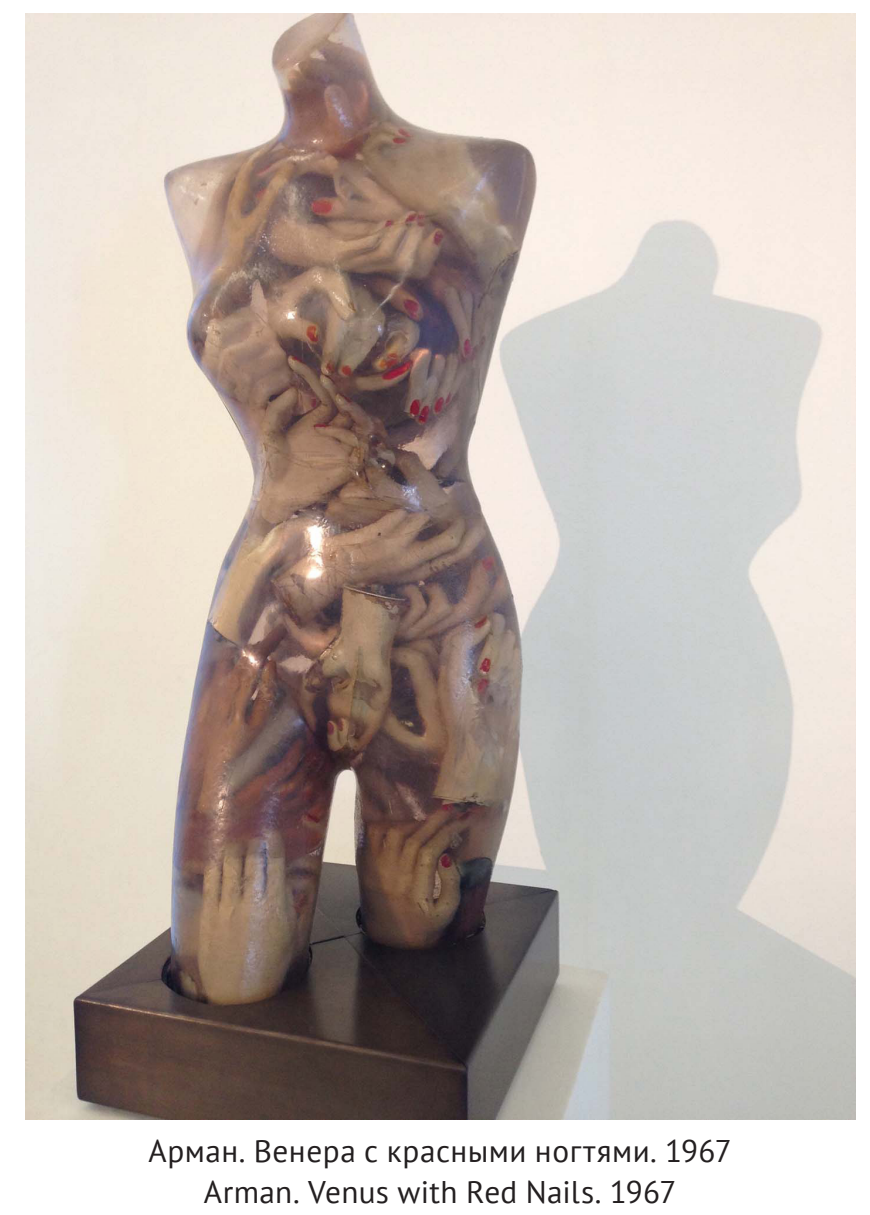

частном пространстве, так и в привычнообиходной городской среде, что произошло с еще одним «памятником», относительно недавно появившимся в столице Франции, скульптурой «Венера искусства» (1993) Venus of the Arts. Так, «критика культуры» (выражение художника) неожиданно (?) для автора оборачивается в определенной степени ее апологетикой.

Также из «мусора», а вернее металлолома, отходов индустриального общества, в определенный период творил свои произведения еще один участник группы «Новые реалисты» Сезар (Бальдаччини) César Baldaccini, 1 (1921-1998). В городском, не камерном выставочном, пространстве (парижская площадь Мишеля Дебре в районе Сен-Жермен) царит «Кентавр» (1983-1984), которого он исполнил по зака- зу Министерства культуры Франции. Пяти метров в длину и полутора в высоту механоморфное создание Сезара составлено из различных бронзовых пластов; детали монументальной металлической конструкции не ассоциируются с отходами, напротив, рождают впечатление процесса творения «здесь и сейчас». Название скульптуры включило дополнение: «Оммаж Пикассо». Энергия и сила, читаемая зрителями при взгляде на «Кентавра», - дань взрывной креативности испанского мастера; память о нем - и голубка на «руке» персонажа. Тем не менее Сезар придал лику своего брутального персонажа автопортретные черты. Совершенно очевидно, что и у Армана, и у Сезара мы отмечаем не только жесты уважения к отцам модернизма, которые так демонстративно отказались от устоявшихся 


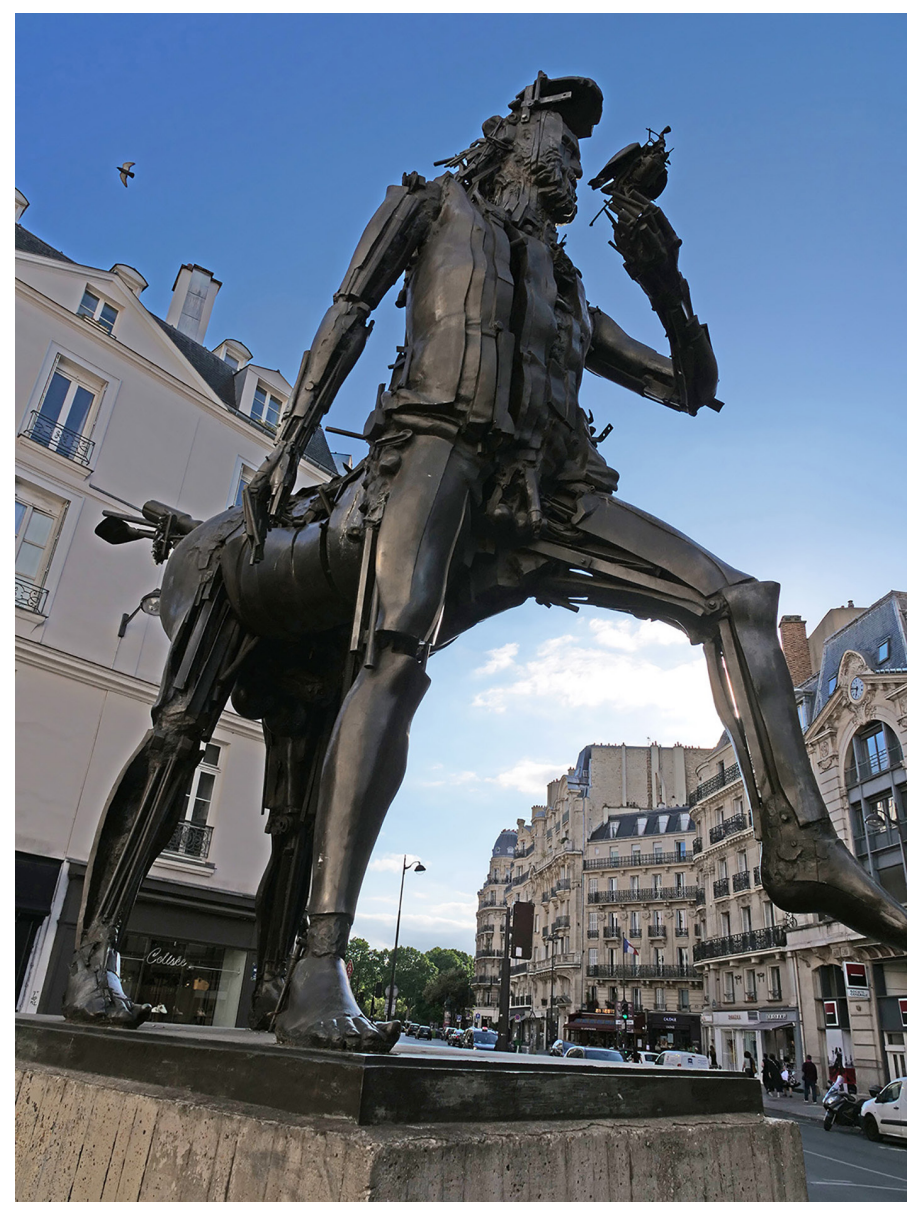

Сезар. Кентавр. 1983-1984. Париж

César. Centaurus . 1983-1984. Paris

взглядов на античное искусство как на идеальный образец, но и стремление к тотальному штурму статичного, стабильного контекста среды посредством собственной, абсолютно специфической, репрезентации хрестоматийных образов.

Ко времени рождения античных творений представителей «новой реальности» уже во второй половине 1970-х годов определилось художественное движение трансавангарда, вполне укладывающееся в рамки постмодернизма. По утверждению его творцов и адептов, художественный язык современности способен обновляться за счет мириад открытий прошлого. «Трансавангард, - объясняет А.Б. Олива «подмеченное» им во множестве визуаль- ных художественных программ современности новое направление, - допускает возможность рассматривать линейновекторный курс, которым следовало искусство на предшествующих этапах, как одну из многих возможностей, направляя свое внимание даже на те языки, которые прежде были отброшены» (Oliva, 2003). Для Италии общественно-исторический контекст Европы 1960-70-х, застигнутой идеологическим, политическим и экономическом кризисом и способствовавшей рождению интернационального трансавангарда, напоминает общеевропейскую ситуацию периода Первой мировой войны и ближайшего послевоенного времени, в частности движения «призыв к порядку» 
(Le Rappel à l'ordre). Однако спустя полвека такое стремление к возврату к вечным ценностям находит объяснение в состоянии, переживаемом европейским сообществом. Кризис позитивизма отражается в кризисе его деривата - исторического новаторства. Полицентризм, отказ от противоборства да и от любой менее агрессивной полемики, по сути, аналогичны восторжествовавшей в лоне западной цивилизации идее политкорректности. Отражаясь на культурном контексте, такая установка, естественно, обусловила проявление самой широкой палитры «воспоминаний», следовательно, самого широкого спектра изобразительных лексем.

Философ и экономист П. Козловски постулирует еще одну важную черту новейшей культуры: «Отношение к классике и традиции должно быть не классическим, a свободным, ироническим» (Kozlovski, 1997). Таким образом, апроприация классики, по заключению теоретика постмодернизма, основана на свободе от пиетета к традиции, а ироничное к ней отношении не позволяет говорить о смысловых реминисценциях. «Анахронизм» (идейной основой которого стала живопись Джорджо Де Кирико «классического периода»), «культурная живопись», «культурные художники», гиперманьеризм и другие термины и понятия, ставшие обозначениями новых процессов, происходящих в мировом искусстве, и обнаруживают частое обращение к античным образам и сюжетам уже в рамках постмодернистской игры с цитатами. Перечисление выставок заставляет вспомнить главы истории искусства. В. Турчин отмечает: «Действительно, вновь встречаем художников с Гомером и историей искусств под мышкой» (Turchin, 1994).

В рамках трансавангарда апеллируют к классике представители итальянского течения «анахронизм», работа представителя которого К.М. Мариани (Carlo Maria Mariani) (р. в. 1931) «Рука, ведомая разумом» LA MANO UBBIDISCE ALL'INTELLETTO (1983) могла бы стать изобразительным эпиграфом к исследованию бытования и функций образов античности в послед- ние десятилетия $\mathrm{XX}$ века. На квадратного формата холсте в стерильном пространстве изображены две почти идентичные «античные» фигуры в скупых драпировках, с обнаженными торсами, увенчанные лавровыми венками, усаженные на шар и куб. В правой руке каждого кисть, которой один из персонажей касается груди своего визави, другой - головы «близнеца», что может означать отсылку к разуму и чувству, авторство каждого и многое другое. Но прежде всего через «классические» образы манифестируются актуальные раздумья о тех итогах, к которым приблизились современные художества, обратившись к воспроизведению бесчисленных культурных матриц. В связи с творчеством Мариани Б. Килерих характеризует общую ситуацию, проявившуюся в искусстве: «Мы ушли от интерпретации истории к истории интерпретаций. Различные версии истины стали истиной версий. Таким образом, все изображения одинаково верны или хороши; это не долгие попытки поиска единственной истины» (Kiilerich, 2007). Яркой особенностью живописи с 1970-х годов является ощущение изобретательной симуляции, изощренной интеллектуальной «игры в бисер» для посвященных (в лучшем случае). O психологизме и драматизме речи нет. Прошлое не уничтожается (так как уничтожение ведет к немоте), а переосмысливается иронично и без наивности. Ирония без наивности в качестве спасительной уловки не предполагает оптимизма, а оказывается симптомом будущей глобальной катастрофы, позывные которой, по всей вероятности, и улавливают художники. Главный смысл эпохи постмодерна, по утверждению П. Козловски, заключается в препятствовании тому, «что собственно должно было наступить после крушения утопических историко-философских ожиданий современности: гибели» (Kozlovski, 1997).

Если отвлечься от эсхатологических идей, которые всегда рождались на рубежах тысячелетий, то в рамках полемики с этим высказыванием можно предположить, что именно адаптация культуры прошлого укрепляет веру (иллюзию?) в возможность 


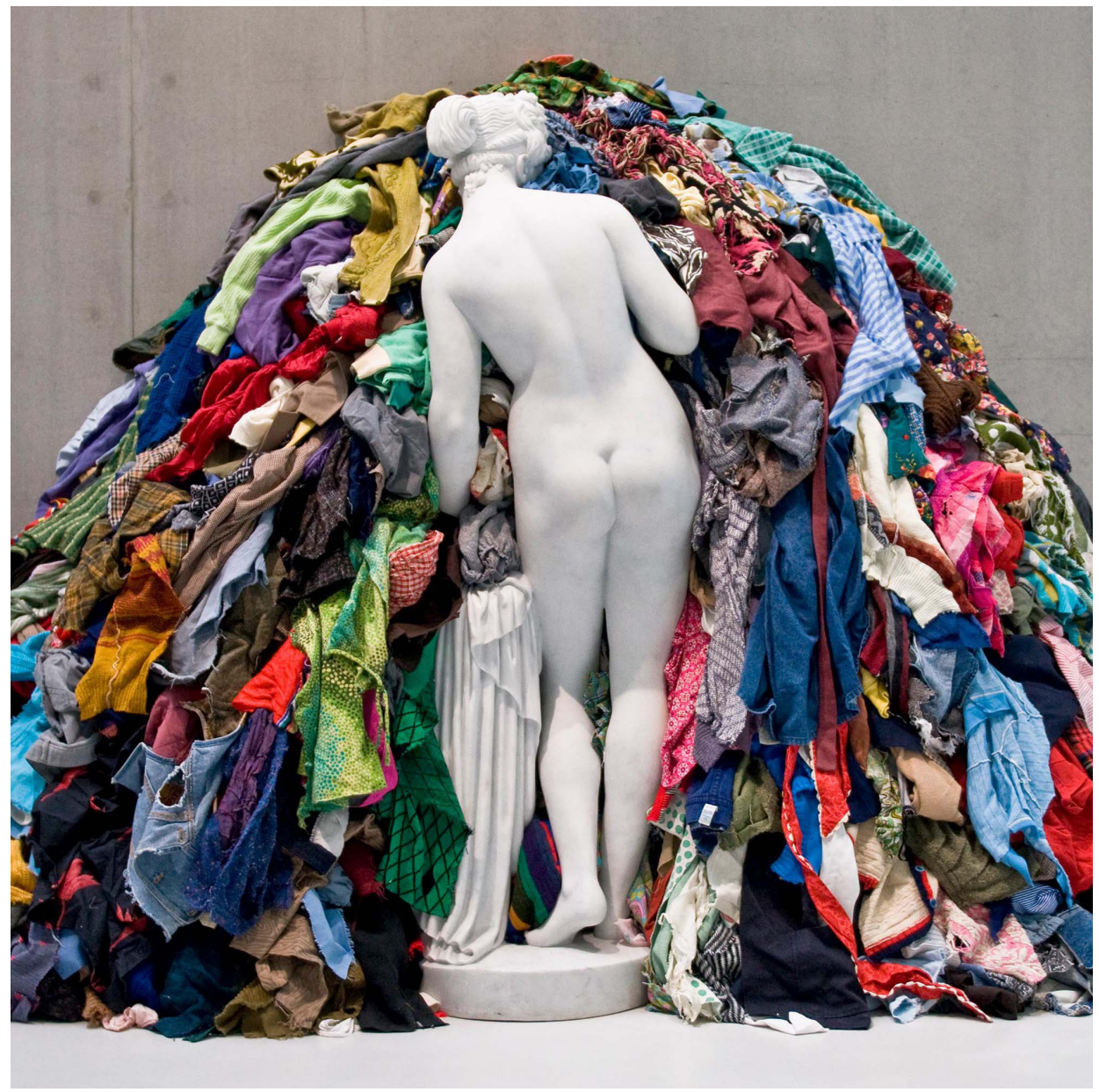

Микеланджело Пистолетто. Венера в лохмотьях. 1967

Michelangelo Pistoletto. Venus of the Rags. 1967

ее охранительных функций, с одной стороны, с другой же - позволяет постоянно задаваться вопросом о сохранности самой культуры и проблеме существования ее в современном мире.

Белоснежную фигуру безрукой Венеры, выполненную в первом варианте из цемента, Микеланджело Пистолетто (р. в 1933) повернул спиной к зрителю и обратил к нагромождению пестрого тряпичного «мусора». Исследовательница современного искусства К. Христов-Бакарджиев видит в комбинации статуи в классическом стиле с пестрой грудой тряпок серию оппозиций: твердое / мягкое, сформированное / несформированное, монохромное / цветное, фиксированное / подвижное, драгоценное / игнорируемое, историческое / современное, уникальное / обычное и культурное. Кроме того, готовность задействовать в искусстве все аспекты жизни (ChristovBakargiev, 1998). Созданная еще в 1967 году в рамках направления «бедное искусство» (arte povera), композиция оказалась богатой на коннотации и актуальной в нашем третьем тысячелетии: она не только стала центром экспозиции, посвященной «Arte Povera» в Галерее Тейт Модерн в 2008 году; кураторы XIV Международной Стамбульской биеннале современного искусства, состоявшейся в 2015 году, сделали ее изобразительным «эпиграфом» к основному 
проекту выставки (он был осуществлен в Стамбульском музее современного искусства).

\section{История и мифы нового тысячелетия}

К концу столетия теоретики постмодернизма обнаруживали яркие тенденции в искусстве, которые, не вызывая сомнения в принадлежности к актуальной современности, все же не подчинялись конвенционным характеристикам. Таково творчество живого классика современности Уильяма Кентриджа (William Kentridge). В 1916 году к 2800-летнему юбилею Рима главным подарком столице Италии стала его монументальная 550-метровая так называемая фреска из грязи, названная автором «Триумфы и поражения» («Triumpfs and Laments») и воскресившая на берегу Тибра картины былой истории. Среди прочих «кадров» на «ленте» стены, нанесенных концентрированными слоями угольной пыли посредством трафаретов и водометов, можно различить капитолийскую волчицу и другие узнаваемые фрагменты великой римской античности. Художник произвел определенного рода наглядную демонстрацию способности человеческой памяти представлять древние, ушедшие в прошлое эпохи и даже вчерашние события в одном ментальном пространстве. И показал власть времени: эфемерная техника, им использованная, предполагает постепенное состаривание изображений с последующим исчезновением. Многое в проекте Кентриджа вполне укладывается в параметры постмодернизма, за исключением принципиального нежелания мастера, сохраняющего динамическую выразительность и легкость художественной манеры, уходить от взволнованной серьезности в беспафосной интерпретации показанного. Эта работа подтверждение тому, что понятие «urbi et orbi» может исключить любые коннотации с поп-культурой.

Апеллируя к массовому сознанию, смешивая, микшируя понятия «высокого» и «низкого», классики и китча, начал свои

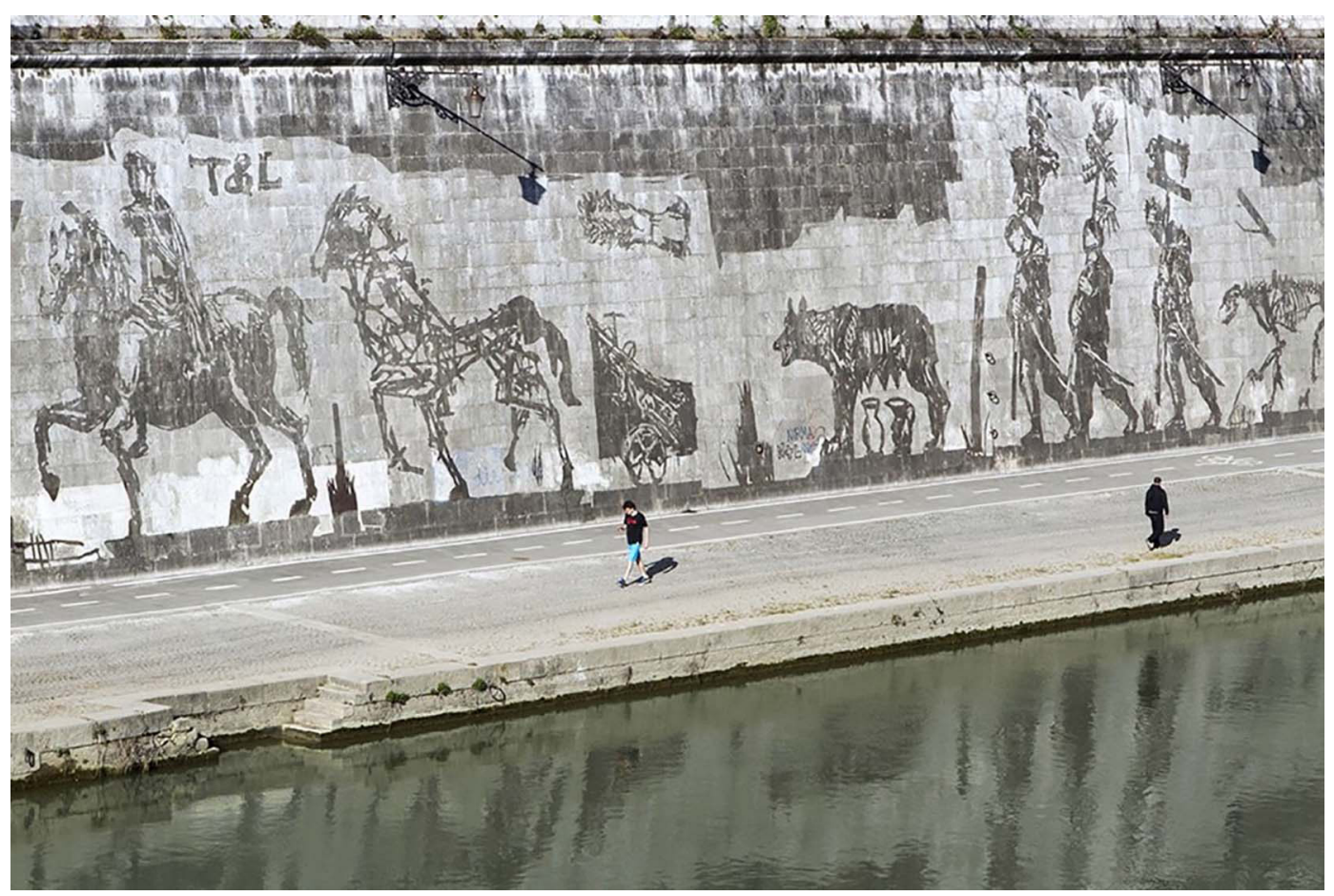

Уильям Кентридж. Триумфы и поражения. Фрагмент композиции. Рим. 2016 William Kentridge. Triumphs and Laments. Rome. 2016 


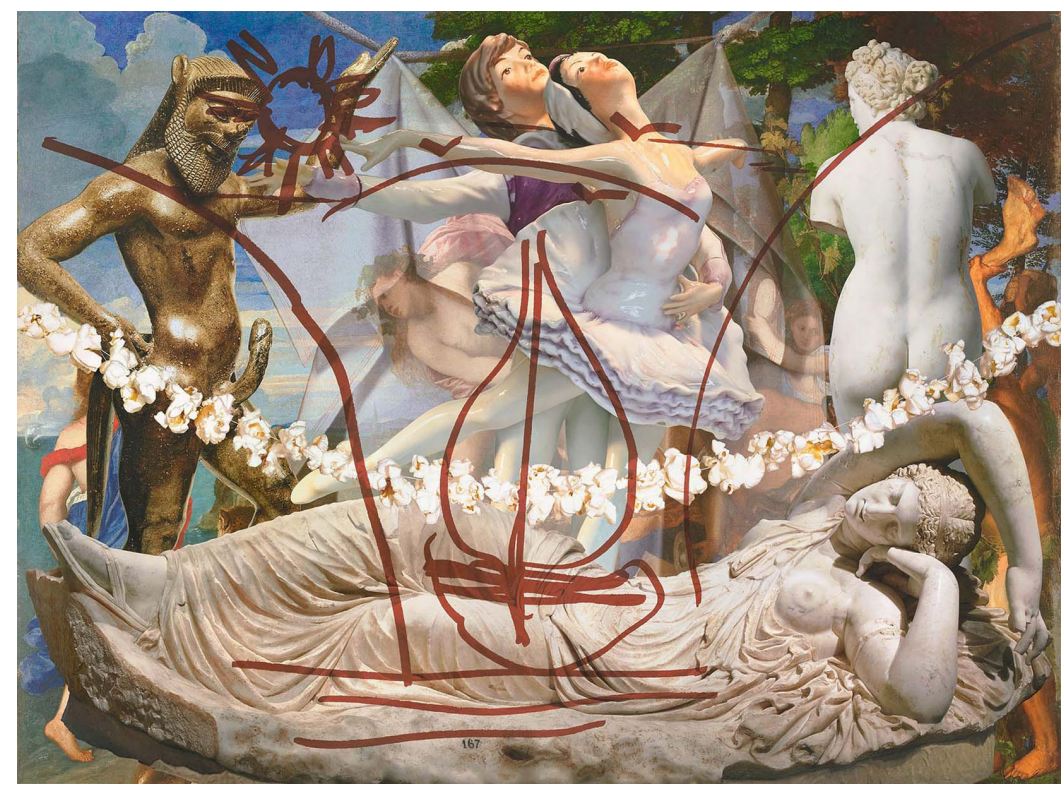

Джефф Кунс. Античность. 2009

Jeff Koons. Antiquity. 2009

игры с античностью в 2009 году серией «Antiquity», продолжающейся по сей день в разных вариантах, американский художник Джерф Кунс (р. в 1955), один из самых ярких акторов в сегодняшнем художественном ландшафте. Зритель, вглядываясь в свое отражение в зеркально-гладкие поверхности ярко-синих (воспоминания о Кляйне?) шаров, которыми были снабжены увеличенные копии античных скульптур, оказывался, таким образом, «апроприированным» скульптурой. В процессе апроприации китча на равных оказывается культурная память и магический банальный, дешевый предмет, который все же под сурдинку звучит интонацией детского праздника и явно медитативного досуга, благодаря прямой ассоциации с садовыми зеркальными шарами. Живописная же часть серии напоминает картины цикла Франсиса Пикабиа 1927-1930 годов «Прозрачности», в каждой композиции которого также царят фигуры, иконографически сходные с известными античными памятниками, окруженные условной пейзажной средой и, главное, очень органично существующие в графической «вуали», более того, ею изо- бражаемые, что позволяет говорить о прямом влиянии классиков модернизма на современного художника, который в отличие от «отцов» свободно оперирует симулякрами и гламурными приемами.

Не скрывается китчевая природа произведений (симбиоз живописи и фотографии), представленной на выставке «Герои» «Héros» (2014) в парижской галерее Даниэля Темплтона («Templton») дуэтом художников Пьера Коммуа (р. в 1950) и Жиля Бланшара (р. в 1953) (Pierre et Giles - именно таким тандемом они выступают). Античные герои, мифологические и исторические, как и библейский Самсон и современные кинокумиры, воплощают торжество обнаженной мужской натуры, а эротические ноты звучат победными фанфарами гей-культуры.

Сложно определить место в современной культуре амбициозного проекта английского художника, предпринимателя и коллекционера Дэмьэна Херста Damien Hirst (p. в 1965) «Сокровища затонувшего корабля «Невероятный»»), «Treasures from the Wreck of the Unbelievable», затеянного Фондом Франсуа Пино François Pinault (он и вложил в проект 50 миллионов 


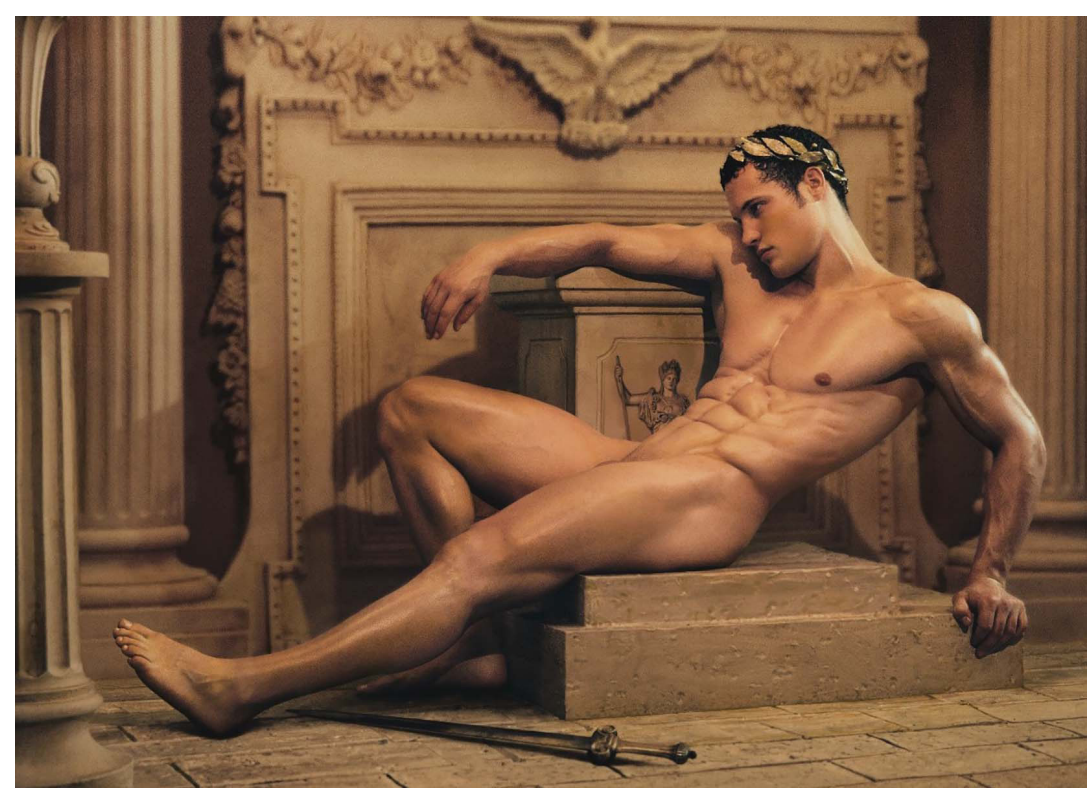

Пьер и Жиль. Орест. 2014

Pierre et Giles. Orest. 2014

фунтов стерлингов). Здесь определение «эклектика», которым с долей условности можно охарактеризовать «античное» творчество в приведенных выше примерах, обретает особую многосложность содержания. Посетителям 57-й Венецианской биеннале (2017) автор предъявил результаты своей 10-летней работы - 189 произведений. В синопсисе выставки, располагавшейся на всех этажах двух зданий, принадлежащих Пино (Punta della Dogana и Palazzo Grassi, общая экспозиционная площадь 5000 кв. м), - фантастическая история о счастливом обретении древних сокровищ со дна Индийского океана, обнаруженных дайверами в 2008 году. Драматургия поддержана видеосъемками, демонстрирующими на больших экранах процесс спасательной операции и создававшими иллюзию документальности. На корабле плыли художественные произведения, монеты, ювелирные изделия, оружие, доспехи, принадлежащие различным цивилизациям всеохватной Античности: римской, галльской, греческой, долины Инда, майя, минойской, египетской и др. Разумеется, океан и время оставили на предметах искусства и высокого ремесла свою причудливую печать - разноцветные раковины, полипы, кораллы и так далее, что придает произведениям особую фантазийную экспрессию и зрелищную «антигламурность». Все экспонаты сработаны из высококачественных, а порой и драгоценный материалов. К экспонатам предлагались экспликации-пояснения, как о происхождении произведений, так и о связи представленных древностей с контекстом искусства и художественной жизни XX века. Так, в связи с «Пятью греческими обнаженными» «Five Greek Nudes» не только говорится о том, что в конце античного периода было исполнено множество копий и версий из представленной серии торсов розового мрамора (так как в то время оригинальности не придавалось значение), но и приводится факт использования одного из таких бюстов на Международной сюрреалистической выставке 1936 года в Лондоне, объясняя популярность арт-объекта в контексте интереса сюрреалистов к манекенам и сексуальности. Великая мистификация Херста, по сути, еще раз предъявляет ответ на во- 


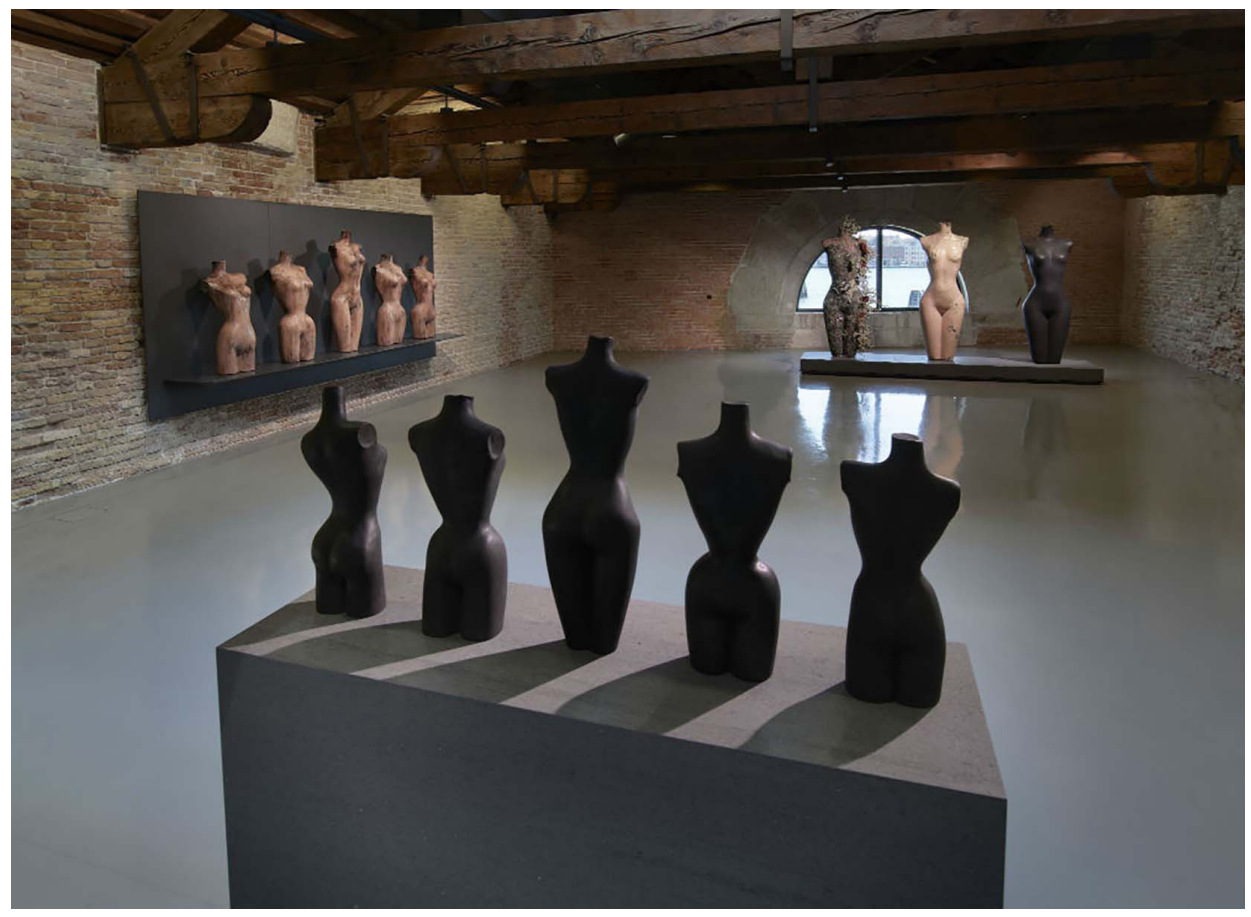

Дэмиен Херст. Фрагмент экспозиции выставки «Сокровища затонувшего корабля «Невероятный»» с вариантами «Пяти греческих обнаженных»

Damien Hirst. Fragment of the exhibition

«Treasures of the sunken ship «Incredible»» with options for «Five Greek nudes»

прос «что такое искусство». По мнению автора, то, во что вы верите. Его альтернативная история, рассказанная посредством артефактов, определялась большинством критиков знакомыми понятием «китч», «фейк», однако весьма убедительными, а сам проект был назван триумфальным.

И до громкого выступления Херста Венецианская биеннале как отражение общих процессов, происходящих в современной культуре, представляла значимые проекты, транслировавшие актуальные смыслы при обращении к культурной памяти об античности. Девятиканальная видеоинсталляция арт-группы $A E S+F$ «Пир Трималхиона» «Feast of Trimalchio» по роману Гая Петрония Арбитра «Сатирикон», исполненная статистами в «люксовых брендах» современности, была показана на 53-й биеннале (2009). В рамках 55-й российский павильон был отдан инсталляции Вадима Захарова «Даная» (Zakharov, 2021).
Пир прожигателей жизни в версии $\mathrm{AES}+\mathrm{F}$ разворачивается в богатом отеле «Трималхион», и на экранах предстает завораживающее зрелище, которое по смыслу вполне сопрягает картины порочного времяпрепровождения «новых римлян» времен упадка империи и современные светские элитарные досуги «все включено». Совершенно очевидно, что гламурное составляющее роскошного dolce far niente здесь - рефлексия на «глянец», царящий во вкусах нашего общества начала тысячелетия. Сегодня в свете недавних событий в США (Black Lives Matter) кадры, в которых «господа» меняются местами со «слугами», видятся пророческими и более шокирующими, чем отсылка к памяти о падении великой страны в далеком прошлом.

\section{Заключение}

Обозначенные в наименовании статьи хронологические рамки вмещают в себя 
не одну эпоху, сменяющиеся актуальные смыслы и вкусовые приоритеты как в социуме, так и в культуре. При этом на всем протяжении десятилетий прослеживается стремление звездных художников Франции, Италии, Испании, Великобритании, России разных поколений и с принципиально различными мировоззренческими основами творчества, включать в свои образные программы античные мотивы, богов и героев, более того, именно их делая трансляторами индивидуальных художественных высказываний, отражающих социокультурную рецепцию.

Можно зафиксировать парадоксальный факт появления впервые за много веков не просто в общественных пространствах, но на городских перекрестках и площадях «античных» скульптур, несущих на себе признаки формальной лексики новых направлений, о которых, впрочем, не задумываются проходящие «среднестатистические обыватели», в чью привычную среду они оказались интегрированными. Стоит вспомнить, что классицистические декоративные скульптуры украшали собой, как правило, сады и парки.

За последние более чем полвека индивидуальные высказывания художников в попытках оставаться в поле полеми- ческого дискурса, в стремлении расширять границы нормы, в том числе недавно утвержденные, состоялись в рамках масштабных (это важно осознавать) концептуальных проектов, тематически полностью основанных на интерпретации образов античности, что происходит впервые в истории выставочной практики. Более того, эти проекты представляются подчас этапными вехами в развитии современного искусства.

Изображение античных образов и мотивов на разных эстетических и мировоззренческих основах присутствуют в экспериментальных произведениях уже ставшего классическим модернизма, в «икарийских играх» клипового постмодернизма (ставшего отражением крушения цельной картины мира, наблюдаемой в современных психологии, философии, истории), оказываются средством актуализации гендерной проблематики, проблем ЛДФ-сообщества, отражением гламурной эстетики, возникают в примерах стрит-арта и арте-повера, элитарной и масскультуры и т. д. Все это позволяет с уверенностью говорить об их актуальности в использовании новых функций и жизнестойкости в художественной практике недавней и сегодняшней современности.

\section{Список литературы / References}

Andreeva, E. (2007). Postmodernizm. Iskusstvo vtoroŭ poloviny XX - nachala XXI veka [Postmodernism. Art of the second half of the XX - early XXI century]. St. Petersburg, Azbuka-klassika, 484 p.

Bachelard, G. (2014). Poetika prostranstva [The poetics of space]. Moscow, Ad Marginem Press, $352 \mathrm{p}$.

Busev, M. (2010). Plasticheskie novat sii Sezara [Cesar's plastic innovations], In Iskusstvo skul'ptury v XX veke: problemy, tendentsii, mastera. Ocherki [The art of sculpture in the twentieth century: problems, trends, masters. Essays]. Moscow, Galart, 473-482.

Busev, M. (2018). Antichnye motivy i obrazy v tvorchestve parizhskikh neoavangardistov: Sezar, Arman [Antique motives and images in the works of Parisian neo-avant-garde artists: Cesar, Armand], In Iskusstvo skul'ptury $v X X-X X I$ vekakh: mastera, tendentsii, problem [Art of sculpture in the XX-XXI centuries: masters, tendencies, problems]. Moscow, BuksMArt, 471-487.

Calinescu, M. (1987). Five Faces of Modernity. Modernism. Avant-Garde. Decadence. Kitsch. Postmodernism. Durham, Duke University Press.

Christov-Bakargiev, C. (1998). Arte Povera (Themes and Movements). London, Phaidon Press.

Christov-Bakargiev, C. (1998). William Kentridge. Brüssel, Palais des Beaux-Arts.

Eko, U. (1998). Zametki na poliakh "Imeni rozy" [Notes in the margins of the "Name of the Rose"]. In Imia rozy [Name of the Rose]. St. Petersburg. 
Getashvili, N. (2016). Vo chto prevretitsa Venera... Obrazy Antichnosti v XX vere [What to turn Venus... Images of antiquity in the art of the twentieth century]. Moscow, BuksMArt, $352 \mathrm{p}$.

Kiilerich, B. (2007). Self-portraiture in Contemporary Italian Art: Giulio Paolini and Carlo Maria Mariani [Self-portraiture in Contemporary Italian Art: Giulio Paolini and Carlo Maria Mariani]. Immagine e ideologia. Studi in onore di A.C. Quintavalle. Milano, Electra, 605-612.

Kozlovski P. (1997). Kultura postmoderna [Postmodern culture]. Moscow, Respublika, 238 p.

Oliva, A.B. (2003). Iskusstvo na iskhode vtorogo tysiacheletia [Art at the end of the second millennium]. Moscow, Khudozhestvenny zhurnal, $217 \mathrm{p}$.

Rose, M.A. (1991). The Post-Modern and the Post-Industrial: A Critical Analysis. Cambridge University Press.

Rykov, A. (2010). Problema skul'ptury v teorii iskusstva Rozalind Krauss [The problem of sculpture in the theory of art by Rosalind Krauss]. In Iskusstvo skul'ptury v XX veke: problemy, tendentsii, mastera. Ocherki [The art of sculpture in the twentieth century: problems, trends, masters. Essays]. Moscow, Galart, 430-439.

Stainberg, L. (2021). Drugie kriterii. Litsom k litsu s iskusstvom XX veka [Other criteria. Face to face with 20th century art]. Moscow, Ad marginem, $424 \mathrm{p}$.

Turchin, V. (1994). Traditsii v avangarde [Traditions in the avant-garde]. In Tvorchestvo [Creation], $1-4,5-8$.

Zadkin, O. (1968). The mallet and the chisel. Memory of my life [Le maillet et le ciseau. Souvenir de ma vie]. Paris, Albin Michel.

Zakharov, V. Danaia [Danaë]. Available at: https://www.safmuseum.org/projects/russian-pavilion/ zakharov-danae.htm (accessed 31 May 2021). 